\title{
DOCUMENTOS
}

\section{Conversación con Borges}

Llego a mi destino: el sexto piso de una casa moderna de la Plaza San Martín, en Buenos Aires. Un simple letrero de bronce en la puerta dice, en letras negras, BORGES. Me siento inquieta y curiosa: hace dos años que no veo a Borges. Me abre la mucama, Fanny, que lleva ya muchos años con la familia. Son las seis de la tarde, una tarde fría de julio, típica del invierno bonaerense. La sala está totalmente oscura. Al principio me imagino que allí no hay nadie. Luego Fanny enciende las luces, y Borges reconoce mi voz. (Casi se me olvidaba que su ceguera es ahora casi total.) Me saluda afectuosamente, recitando un viejo poema de bienvenida, con su tono especial, casi hipnótico, casi ritual. Charlamos y reímos recordando sus seminarios acerca de Beowulf, hace ya muchos años. Físicamente sigue tan atractivo como siempre. Sus grandes ojos son de un verde muy claro, como los de su madre. Se pasea por la sala con facilidad: cada objeto, cada mueble, le es familiar, sabe evitar sillas y mesas; nadie diría, al verlo, que está ciego. Nos sentamos los dos en el sofá de terciopelo oscuro y empezamos a conversar: cuando se da cuenta que estoy grabando la entrevista se interrumpe y me pide que volvamos a empezar desde el principio. $Y$ repito la primera pregunta: esta vez su respuesta es precisa, equilibrada, bien compuesta, como cuando solía dictarme, hace de esto bastantes años, sus famosos cuentos. Habla con rapidez - al contrario de su ritmo en sus conferencias públicas - y sus manos, siempre expresivas, revolotean por el aire cada vez que quiere subrayar una idea. Pero el resto de su cuerpo permanece inmóvil: con el bastón entre las piernas, me mira fijamente, sin verme, y habla. Su aspecto es saludable: nada en su expresión revela una nota trágica o patética. Con personas que conoce bien, se siente a gusto, se complace en contar chistes o hacer juegos de palabras. Le encantan los chistes políticos: se ríe sonoramente, con deleite, tras cada chiste o tras una observación ingeniosa. Pero si la persona que lo entrevista - como ocurre con frecuencia - le es desconocida, se mantiene tenso, casi molesto, como si su público fuera una muchedumbre exigente. Conmigo se siente a gusto y se permite comentarios difíciles de publicar, ya que implican a 
otras personas que viven todavía, o enjuician con gran dureza lo que estas personas han escrito. Lo esencial es que sigue siendo tan ingenioso y tan irónico como en el pasado: es uno de los conversadores más simpáticos y divertidos que conozco. Pocos pueden transmitir a su interlocutor una sensación tan clara de inteligencia alerta y profunda, un pensamiento generoso, y una selección cuidadosa de palabras, hecha siempre con originalidad. Su forma de expresar y organizar la vastísima cultura que posee es tan discreta que uno no se da cuenta de que esa cultura está allí, en él, animando y dirigiendo su pensamiento. Su excelente memoria le permite citar las fuentes más diversas para ilustrar una idea, un comentario. Borges y yo seguimos;charlando:

S.Ch.S.: Borges: ¿Piensa usted más frecuentemente en el pasado que en el futuro?

J.L.B.: Sí, pienso en el pasado porque el pasado es real, está lleno de personas interesantes; por ejemplo, Stevenson, por ejemplo Platón, por ejemplo Swedenborg, por ejemplo Berkeley.

S.Ch.S.: Pero quizá el futuro también esté poblado de gente interesante...

J.L.B.: Sí, ya sé, pero como no los conozco, como no me han sido presentados...

S.Ch.S.: Sí, es cierto.

J.L.B.: Lo único que sé del futuro es que no se parecerá al presente. Además que hablar del futuro es simplificar mucho las cosas. Habrá muchos futuros que no se parecerán entre sí, de igual modo, digamos, que el siglo dieciocho no se pareció al siglo diecisiete. Yo no puedo interesarme en algo tan abstracto como esto. Yo soy una persona casi incapaz de pensamiento abstracto.

S.Ch.S.: Caramba, pero eso que usted me dice es rarísimo...

J.L.B.: No, no, en absoluto. Usted ve que aunque a mí me ha interesado mucho la filosofía y la metafísica, al fin de todo, eso es una serie de perplejidades organizadas, o si no, formas de literatura fantástica, como en el caso de la teología... En todo caso, el pasado me parece más real. Desde luego, el futuro depende del presente, en función del futuro. Por ejemplo: hay un libro - que no admiro demasiado - Brave New World, que no se parece en nada a lo que puede ser el porvenir, es simplemente un presente exacerbado; además, no está hecho - a la manera de Wells - a modo de profecía, sino que es una sátira del futuro.

S.Ch.S.: Entonces ¿Usted no cree que ese mundo de nuestro futuro se parecerá al mundo de Brave New World?

J.L.B.: Claro que no, porque el mundo de Brave New World se parece demasiado al mundo del siglo veinte. Por ejemplo, la gente, hoy día, está muy interesada en party politics; en un futuro quizá dejen de estar interesados en esto. Yo he vivido cinco años en Suiza. Cuando llegamos, 
pregunté quién era el presidente, la gente me miró extrañada porque nadie sabía quién era...

S.Ch.S.: Pero eso es increíble.

J.L.B.: No, porque en Suiza los políticos no son personajes públicos. Son funçionarios que ejercen sus funciones, pero nadie se ocupa especialmente de ellos. Yo recuerdo que en la movilización del año 1914 se movilizaron doscientos mil hombres, pero había sólo tres coroneles en el ejército, y uno de ellos aceptó ser general con una condición: que no le aumentaran el sueldo. Y en Ginebra, que era una cuidad de, digamos, ciento sesenta mil habitantes, había un comisario y dos vigilantes. Entonces, en el mundo que se dará eventualmente, la gente dejará de estar interesada en todo esto. Estará interesada en otras cosas: en la filosofía, en la ciencia, y ¿por qúe no?,en el ajedrez también. Quiero decir - y esto quizá sea inevitable - que nosotros tendemos a considerar el futuro desde el punto de vistadel presente. Por ejemplo, vamos a suponer una persona durante la época del protestantismo: habría pensado que en el siglo XX lo que interesaría a la gente sería el hecho de si alguien es discípulo, bueno, discípulo de Calvino ode Wycliffe,o de Lutero o simplemente católico. Y ahora esto, como usted sabe, no interesa a nadie. Supongo que con el porvenir, o con los porvenires, porque esa palabra de porvenir me parece, bueno, too sweeping a statement...el futuro tendrá sus problemas propios. Ahora nos interesa la tarea de llevar hombres a la luna. Pero llegará, indefectiblemente, ese momento, y ya Spengler lo ha dicho, en que al hombre le interesarán cosas que no podemos imaginar ahora, de igual modo que Platón no pudo imaginar lo que sería el mundo actual.

S.Ch.S.: Pero a usted, entonces, ¿no le interesaría en absoluto vivir en el mundo del siglo XXX?

J.L.B.: No, porque no entendería nada. La gente estaría interesada en temas que no podrían interesarme a mí. Desde luego, creo que los problemas de la filosofía son insolubles, porque yo soy agnóstico.

S.Ch.S.: ¿Usted es agnóstico?

J.L.B.: Sí, claro. Creo que esos problemas se plantearán dentro de mil años de un modo distinto, que yo no podré comprender, de igual modo que yo no sé hasta qué punto Platón hubiera podido seguir los argumentos de Berkeley, o Berkeley entender los de Bergson, o, en general, el mundo de Henry James.

S.Ch.S.: Borges, usted dice en uno de sus cuentos: "como a todos los hombres, le tocaron tiempos difíciles en que vivir".

J.L.B.: Sí, eso es verdad...

S.Ch.S.: ¿Se acuerda de eso? ¿Sigue pensando que todos los tiempos serán difíciles, todos los tiempos del futuro? 
J.L.B.: Sí, para ellos sí, definitivamente. Pero todo esto ya lo discutió Schopenhauer, quien dijo que el presente es siempre difícil, porque lo vivimos como un conflicto. En cambio, el pasado es algo que uno ve como una lámina o como un cuadro, es decir, del pasado está ausente la voluntad. Podemos ver el pasado con gusto. Hasta podemos pensar románticamente en épocas atroces, como la época de la dictadura de Rosas aquí, como en algo pintoresco. Quizá nuestra época sea vista como pintoresca en el porvenir. Pero nosotros, que tenemos que vivirla, no la sentimos como pintoresca, la sentimos como algo atroz. Un caso bastante reciente: los contemporáneos de Napoleón vivieron bajo un sistema policíaco, pero luego vino Víctor Hugo, luego vinieron los románticos, y todo eso se vuelve una época espléndida. Ciertamente no una época para padecer.

S.Ch.S.: ¿Cree usted que los seres humanos no cambian? ¿Qué no habrán aprendido a ser menos agresivos o menos violentos?

J.L.B.: No, pero tendrán otros problemas. Por ejemplo, es probable que desaparezcan las guerras. Podrá llegarse a considerar un gobierno central, o una situación donde no se necesite gobierno.

S.Ch.S.: Pero no existen naciones donde no se necesite gobierno...

J.L.B.: Pero ya hay países, como los países escandinavos, donde no hay criminalidad. En Islandia tampoco. Usted me dirá que hay otras cosas, como por ejemplo, alcoholismo...

S.Ch.S.: Y también un índice altísimo de suicidios..

J.L.B.: ¡Ah! Pero esas son personas que demuestran buen sentido. No esperan a que les suceda nada.

S.Ch.S.: Sí, quizá sea un síntoma de inteligencia.

J.L.B.: Claro, yo creo que sí. Eso de suicidarse es lo más sensato y lo más calmoso que pueda hacerse. Una prueba de serenidad. $Y$ hablando de suicidio, creo haber leído en Schopenhauer, quien cita en Paralipómena, en su artículo 'Uber der Selbsmord', que había una ciudad en Grecia donde la gente que creía tener motivos para suicidarse, podía exponer su caso ante un tribunal. Digamos, gente con una enfermedad incurable o lo que fuera. Y si el tribunal juzgaba que estaba bien, que tenían razón, se les entregaba la cicuta. Y esto no era mal visto. Porque, en general, el suicidio ha sido muy mal visto, digamos, por el Cristianismo. $Y$ es raro, porque el Cristianismo, que cuenta al fin con un Dios suicida, -porque se entiende que Cristo se suicidó - hace, sin embargo, que se venere la cruz, que es el instrumento del suicidio de Jesús.

S.Ch.S.: Bueno, quizá como en su cuento "Utopía para un hombre que está cansado" puede existir el suicidio como una salida de elección. 
J.L.B.: Sí, exactamente. Allí, cuando él siente que ha agotado sus posibilidades, cuando está cansado, se suicida. Además, y esto me parece una idea muy buena, in order not to encumber the future, hace que toda su obra sea destruida con él. Yo he sido amigo de muchos suicidas, he sido lejanamente amigo de Lugones...lejanamente, digo, porque Lugones era un hombre soberbio, solitario...pero yo no pienso en ellos como personas culpables. El caso de Lugones es interesante. El se jactaba de ser el marido más fiel de Buenos Aires, y era, además, un puritano. Incluso parece que llegó virgen al matrimonio. Luego, cuando se enamoró de una mujer y ésta lo abandonó, se suicidó...Pero debiera haber sabido que esas cosas pasan con el tiempo, y que, sin duda, él también había dejado muchas mujeres. Pero claro, su problema, creo yo, es que se sentía admirado, pero no querido. Y ser querido es muy importante. Ser admirado y no ser querido es my triste.

S.Ch.S.: Entonces, Borges ¿a usted no le interesa ser célebre?

J.L.B.: No, claro que no, más bien lo veo como una forma de incomodidad. Siempre me ha sorprendido el interés de la gente por la fama. Ahora se ha inventado una palabra que a mí me parece casi infame: promocionar. Una escritora amiga me dijo: yo voy a tal Congreso, son todos una serie de canallas o de imbéciles, pero lo necesito para mi promoción. ¿Para qué seguir dialogando con gente asi?

S.Ch.S.: Bueno, es verdad, son las sociedades del autobombo mutuo. Pero hay una pregunta que a mí me gustaría hacerle sobre elfuturo.¿Cree usted que se seguirá hablando de amor, se seguirá hablando de amistad?

J.L.B.: Pero desde luego, ¿cómo no se va a hablar de eso?

S.Ch.S.: No sé, porque hay gente que opina que podrá haber un control biológico, un control administrativo, por ejemplo...

J.L.B.: Ah, pero son personas muy pesimistas. Además sería muy raro un hombre que no necesitara amor o no necesitara amistad. Sería un ser rarísimo. Y si es así, ¿para qué conocerlo, qué nos importa lo que le pase?

S.Ch.S.: Hay gente que habla de una sociedad de robots, totalmente mecanizada.

J.L.B.: Sí, pero es que la idea de la máquina es una idea actual. Va a ver usted que no va a interesar en el porvenir. Frankenstein es también una idea actual, igual que el robot. A menos que se los utilice para ciertas tareas, eso podría ser...

S.Ch.S.: ¿Cree usted que se podría limitar la educación a unas cuantas personas capaces de programar máquinas cibernéticas?

J.L.B.: Pero es un absurdo pensar que las máquinas van a resolver las cosas. Usted ve, cuando empezó el cine yo recuerdo que se dijo que iba a ser la muerte de los actores. Pero no se ve gente que aplauda un fonógrafo o una 
máquina de fotografía: se aplaude más bien un actor. Uno no dice: tal cosa es cierto, lo dice la radio. Es como si usted me dijera: tal cosa es cierto: lo dijo el teléfono. Es absurdo.

S.Ch.S.: ¿Cree usted que no será un crimen ser individual? ¿La famosa masificación de la cual se habla no existirá en el futuro?

J.L.B.: Creo que cuando yo estaba en un Congreso en Washington alguien me dijo: ¿qué opina usted de la masa? Y yo le contesté: yo no entiendo de conceptos abstractos, pregúnteme sobre algún individuo, porque la masa no existe, $\mathrm{y}$ además a la gente no le gusta sentirse masa.

S.Ch.S.: Entonces habrá literatura...

J.L.B.: Pero claro, y música y pintura. La literatura es una de las necesidades del hombre. El arte, la pintura, sin duda, van a ser mucho más complejos que ahora. Con todo respeto por Homero, creo que un cuento de Henry James es mucho más complejo, aunque no superior. Las artes, para desarrollarse, estarán más allá de lo que nosotros podamos entender. Serán una cosa distinta. Es lo que sucederá con la gente. Si se mantiene la cronología actual, no creo que el siglo, digamos XXIV se entienda muy bien con el siglo XXIII. Tampoco me imagino a un poeta anglosajón o a un escritor escandinavo del siglo XXXIII, en fin, no creo que pudiera entenderlo a Flaubert, o a Meredith o a Proust.

S.Ch.S.: Hay personas que piensan que se les prohibirá escribir a los escritores.

J.L.B.: No lo creo. Eso sólo podría suceder en países muy atrasados como Rusia.

S.Ch.S.: Esto es relativo, porque en Hungría ha habido un verdadero renacimiento del teatro, por ejemplo, y el gobierno no les molesta en absoluto.

J.L.B.: Caramba, me parece una excelente noticia. Yo creí que allí estaría todo masificado, como dice usted.

S.Ch.S.: Borges, quiero hacerle una de las últimas preguntas: ¿Cree usted que seremos todos de una sola raza, through miscegenation, o seremos dominados por una raza en particular, a raiz del exterminio y de la conquista de las demás? ¿Hay posibilidades de que, por ejemplo, los chinos dominen el mundo?

J.L.B.: Bueno, es que quizá los chinos son la civilización más antigua. Prescindiendo de la política actual, que no conozco, y a juzgar por Confucio, son gente esencialmente razonable. Por ejemplo, si uno compara las Analectas de Confucio, con los Evangelios, éstos parecen superiores, no por lo que dicen, sino porque son más patéticos. Pero en cuanto a las ideas, uno se da cuenta de que eran muy razonables. 
S.Ch.S.: Existiría, quizá, la posibilidad de que todas las razas coexistieran sin problemas y sin temores?

J.L.B.: Sí, yo creo que sí. Xul Solar siempre decía que la Argentina necesitaba ser un país más cosmopolita. Porque aquí ¿qué hay? decía: gringos y gallegos. Tienen que venir malayos, chinos, árabes, judíos.

S.Ch.S.: Judíos hay muchos en Buenos Aires. Medio millón, por lo menos.

J.L.B.: Es cierto. Y es un pueblo a quien le debemos la Biblia y el ser quienes somos, porque al fin y al cabo la cultura occidental iqué es, sino una especie de conciliación de Grecia con Israel? o de Israel con Roma, que es una sucursal de Grecia. En realidad, you can think the English away, or even the French away, but you can't think the Jews away. El único argumento que habría contra los judíos es el antisemitismo. Por ejemplo, yo no sé si hay judíos en Groenlandia, pero si que sí los hay, habrá también antisemitas. El hecho de que un pueblo no sea querido, de algún modo es un argumento contra él.

S.Ch.S.: Pero usted ha sido siempre pro-semita...

J.L.B.: Sí, es verdad, soy pro-semita, y creo ser parcialmente semita, aunque no tengo una seguridad absoluta...

S.Ch.S.: ¿Por qué cree usted ser parcialmente semita?

J.L.B.: Porque mi apellido es Acevedo y es, desde luego, un apellido portugués que fue usado por muchos judíos. Hay un cuento, en que un judío askenazy se hace pasar por sefardita, para darse corte, y utiliza después el apellido Souza-Acevedo. Es, sin duda, de los países civilizados más antiguos del mundo.

S.Ch.S.: Borges, una última pregunta: ¿cree que en el mundo del futuro existirán todavía los sexos?

J.L.B.: Bueno, let's hope so, eh? Let's hope so.

Yale University

SUSANA CHICA SALAS 
